\title{
Lasting effect of soil warming on organic matter decomposition depends on tillage practices
}

\author{
Ruixing Hou ${ }^{\text {a, b }}$, Zhu Ouyang a, b, *, Dorodnikov Maxim ${ }^{c}$, Glenn Wilson ${ }^{\mathrm{d}}$, \\ Yakov Kuzyakov ${ }^{\mathrm{c}}$ \\ ${ }^{a}$ Key Lab. of Ecosystem Network Observation and Modeling, Institute of Geographic Sciences and Natural Resources Research Chinese Academy of Sciences, \\ Beijing 100101, China \\ ${ }^{\mathrm{b}}$ Yucheng Comprehensive Experiment Station, China Academy of Science, Beijing 100101, China \\ ${ }^{c}$ Department of Soil Science of Temperate Ecosystems, University of Göttingen, 37077 Göttingen, Germany \\ ${ }^{\mathrm{d}}$ USDA-ARS, National Sedimentation Lab, Oxford, MS 38655, USA
}

\section{A R T I C L E I N F O}

\section{Article history:}

Received 24 July 2015

Received in revised form 9 December 2015

Accepted 17 December 2015

Available online 19 January 2016

\section{Keywords:}

Thermal adaptation

Warming

Extracellular enzyme activity

No-till

Soil organic matter

$Q_{10}$

\begin{abstract}
A B S T R A C T
Global warming accelerates soil organic matter (SOM) decomposition with strong feedback to atmospheric $\mathrm{CO}_{2}$. Such an effect should be especially important for no-till agricultural practices, where SOM accumulates in the topsoil as compared with conventional tillage. We incubated soil samples $(0-5 \mathrm{~cm})$ at three temperature levels $\left(15,21\right.$ and $\left.27^{\circ} \mathrm{C}\right)$ from long-term till and no-till systems that were in situ warmed and non-warmed to assess the temperature sensitivity of $\mathrm{CO}_{2}$ efflux, labile organic carbon and extracellular enzyme activities. Thermal adaptation to prolonged warming was observed resulting in a lasting effect on SOM decomposition. On average, 26, 14 and $12 \%$ more $\mathrm{CO}_{2}$ was emitted at each incubation temperature from the warmed soils compared to the non-warmed soils. The $Q_{10}$ value was lower for the warmed than the non-warmed soils. Soil microbial biomass $C$ and dissolved organic $C$ declined with warming. The activities of three extracellular enzymes, $\beta$-glucosidase, chitinase, and sulfatase, were higher under warming and no-till as compared to non-warmed and tilled soil. We concluded that the increased SOM decomposition due to the stimulation of microorganisms by warming was long-lasting. Predictions of $\mathrm{C}$ accumulation in the topsoil by no-till farming should be taken with caution, as this $\mathrm{C}$ pool is especially vulnerable to global warming.
\end{abstract}

๑) 2016 Elsevier Ltd. All rights reserved.

\section{Introduction}

Given the tremendous amount of organic carbon (C) in soil, understanding the feedback between soil organic matter (SOM) decomposition and global warming is critical for predicting future atmospheric $\mathrm{CO}_{2}$ concentrations. The response of SOM decomposition to temperature changes has received considerable attention during the last decade (Melillo et al., 2002; Davidson and Janssens, 2006; Allison et al., 2010). How long the effects of warming could last on decomposition remains unclear: will this effect be ongoing for extended periods, or will the processes adapt to the warmer conditions and stabilize to the previous decomposition level after

\footnotetext{
* Corresponding author. Key Lab. of Ecosystem Network Observation and Modeling, Institute of Geographic Sciences and Natural Resources Research Chinese Academy of Sciences, Beijing 100101, China. Tel.: +86 01064856514; fax: +86 01064854230.

E-mail address: ouyz@igsnrr.ac.cn (Z. Ouyang).
}

exhausting available organics? Numerous studies have reported that increased temperature significantly alters microbial community structure and functioning by affecting substrate and nitrogen availability (Melillo et al., 2011; Bradford, 2013; Steinweg et al., 2013; DeAngelis et al., 2015). However, an understanding of microbial feedback to global warming remains limited, especially for the utilization of substrate and microbial activity associated with soil C cycling (Wallenstein et al., 2009).

Microbial controls on soil $\mathrm{C}$ cycling can be affected by global warming, primarily through two mechanisms. First, microbiallydriven decomposition of SOM is regulated by the quantity and quality of substrates comprising the SOM, which can be affected by temperature increase. Warming often results in an increase in substrate input from litter and root exudates due to an increase in plant growth (Oberbauer et al., 2007). Warming can also stimulate the use of the easily available SOC pool, change the microbial community structure, and lead to an alteration in C use by microorganisms. There are debates on the relationship between the 
decline in available substrates and weaker response of warminginduced soil respiration (Bengtson and Bengtsson, 2007; Fissore et al., 2013). Second, warming may increase microbial activity, leading to acceleration of SOM decomposition. This acceleration may come from long-term (Billings and Ballantyne, 2013) or temporary thermal adaptation of the microbial community to the warmer conditions (Bradford, 2013). An increasing number of studies have shown that warming changes microbial community structure, and warming increases the rate of enzymaticallycatalyzed reactions up to a temperature optimum (Wallenstein and Weintraub, 2008; Burns et al., 2013). However, only a few studies have measured extracellular enzyme activities (EEA) in field warming experiments and just some of those studies found warming to have a consistent positive effect on EEA (Bell and Henry, 2011; Jing et al., 2014; Schindlbacher et al., 2015). A reliable and sensitive proxy for the total microbial activity is the activity of key enzymes responsible for nutrient acquisition by microorganisms and SOM degradation.

No-till (No-Till) farming sequesters more $C$ close to the soil surface than does conventionally tilled (Till) farming, whereas Till stores more C deeper in the profile (Baker et al., 2007; Hou et al., 2012). However, the fate of this surface-sequestered $C$ in No-Till soil is unclear under warming and post-warming conditions. To better project the responses of SOM decomposition under two tillage systems to future warmer world, we incubated the topsoil $(0-5 \mathrm{~cm})$ from four years in situ warming filed experiment, analyzed the released $\mathrm{CO}_{2}$ at three temperatures $\left(15,21\right.$ and $\left.27^{\circ} \mathrm{C}\right)$ and estimated the temperature sensitivity of SOM decomposition $\left(Q_{10}\right)$. The objective of this study was to determine the lasting effect of warming on microbial activity under long-term No-Till and Till management systems to answer the following research questions: (i) is there a difference in $\mathrm{CO}_{2}$ production and extracellular enzyme activities between in situ warmed and non-warmed soils? (ii) are the differences in $\mathrm{CO}_{2}$ and enzyme activities temperature sensitive and (iii) are the sensitivities dependent upon the tillage system?

\section{Materials and methods}

\subsection{Site description}

This study was conducted on long-term (since 2003) experimental field plots in the North China Plain (NCP) $\left(36^{\circ} 50^{\prime} \mathrm{N}\right.$, $116^{\circ} 34^{\prime} \mathrm{E}, 20 \mathrm{~m}$ above sea level). The site is located in a temperate semi-arid climate, with an annual mean temperature of $13.6^{\circ} \mathrm{C}$ and mean precipitation of $553 \mathrm{~mm}$ during the past 29 years (from 1985 to 2013). Approximately $70 \%$ of the annual precipitation occurs between June and September. The soil is classified as a Calcaric fluvisol according to the FAO-UNESCO system, and the surface soil texture is silt loam ( $12 \%$ sand, $66 \%$ silt; $22 \%$ clay), according to the USDA classification system, with a $\mathrm{pH}$ of 6.9. Winter wheat (Triticum aestivum L.) and summer maize (Zea mays L.) were double cropped, which is common in the NCP. Depending on precipitation, winter wheat was irrigated two to three times each season (70-80 $\mathrm{mm}$ each time), while summer maize was irrigated only in dry summers. Each year, crop residues (including straw and stover) were retained on the soil surface for No-Till but removed for Till. The study involved four treatments: Till with and without warming (TW and TN, respectively) and No-Till with and without warming (NW and NN, respectively). The warmed block in each pair was continuously heated using an MSR-2420 infrared heater (Kalglo Electronics Inc., Bethlehem, PA, USA) beginning on the 4th of February, 2010. The infrared heater was placed $3 \mathrm{~m}$ above ground. Soil moisture and temperature were measured by probes at $5 \mathrm{~cm}$ depth. The details of the set-up are provided in the previous study of the same field (Hou et al., 2014).

\subsection{Sampling and incubation}

Soil samples $(0-5 \mathrm{~cm})$ were taken on 13th May, 2013 and stored at $4{ }^{\circ} \mathrm{C}$ before incubation. Soil sampled from the four long-term field treatments (TN, TW, NN, NW) were weighed in equivalent 30 -g air-dried soil samples and placed into air-tight vessels $(120 \mathrm{ml})$. These samples were incubated at 15,21 and $27^{\circ} \mathrm{C}$ for 59 days, with four replications for each treatment and temperature. The soil moisture was kept at $70 \%$ of its water holding capacity (i.e. $30 \%$ gravimetric moisture content) with deionized water. Thus, the microbial activities observed were in response to the soil properties established by the long-term management systems and exposure or non-exposure to warming at the time of sampling.

\subsection{Measurements}

Soil $\mathrm{CO}_{2}$ efflux was trapped by $3 \mathrm{ml}$ of $1 \mathrm{M} \mathrm{NaOH}$ in small vials placed in vessels. The traps were changed eight times during the 59-day incubation, and the $\mathrm{CO}_{2}$ efflux was determined. The temperature sensitivity $\left(Q_{10}\right)$, which is a measure of the rate of a parameter change as a consequence of increasing the temperature by $10{ }^{\circ} \mathrm{C}$, was estimated based on the $\mathrm{CO}_{2}$ fluxes at three temperatures at the beginning and end of the incubation periods (0-6th day and 35th to the 59th day, respectively). Mean respiration rates at each incubation temperature were fitted with an exponential model to calculate $Q_{10}$ value:

$R \mathrm{~s}=a e^{b T}$
$Q_{10}=e^{10 b}$

where $R$ s is soil respiration, $T$ is soil temperature, and $a$ and $b$ are two regression coefficients (Luo et al., 2001).

Soil $\mathrm{pH}$ was measured using a $1: 2.5(\mathrm{w} / \mathrm{v})$ soil to $0.01 \mathrm{M} \mathrm{CaCl}_{2}$ ratio with a glass electrode. The concentrations of soil organic $\mathrm{C}$ and total N were determined with a LECO CN2000 analyzer. Soil microbial biomass carbon (MBC) and $\mathrm{K}_{2} \mathrm{SO}_{4}$-extracted carbon - dissolved organic carbon (DOC) were determined by the fumigationextraction method before and after incubation (Vance et al., 1987). A $K_{C}$ value of 0.45 was used to calculate the $C$ content of the SMBC, and this factor was empirically defined in earlier studies (Vance et al., 1987) based on cell survival after fumigation with chloroform to correct for the carbon that could not be extracted.

To analyze the responses of microorganisms to warming, the activity of three extracellular enzymes was determined: $\beta$-Glucosidase, N-acetyl- $\beta$-D-Glucosaminidase (chitinase) and sulfatase, which reflect $C$ ( $\beta$-Glucosidase, chitinase), $N$ (chitinase) and $S$ (sulfatase) cycling, respectively. Extracellular enzyme activities were measured using fluorogenically labeled substrates according to a modified technique (Marx et al., 2001; Stemmer, 2004). Three fluorogenic enzyme substrates based on 4-methylumbelliferone (MUF) were used: MUF-b-D-glucopyranoside (MUF-G; EC 3.2.1.21, for the detection of b-glucosidase), MUF-N-acetyl-b-D-glucosaminide dihydrate (MUF-NAG; EC 3.2.1.14) for chitinase, and MUFsulfate potassium salt (MUF-S; EC 3.1.6) for sulfatase activity. To dissolve the MUF-substrates, $2 \mathrm{ml}$ of 2-methoxyethanol was used. Pre-dissolved MUF-substrates were further diluted with sterile distilled water to give the desired concentrations. The soil samples $(1 \mathrm{~g})$ were suspended in water $(20 \mathrm{ml})$ and shaken on an overhead shaker for $15 \mathrm{~min}$ at room temperature at maximum speed to ensure thorough mixing. A subsample of the soil suspension $(50 \mu \mathrm{L})$ was added to $100 \mu \mathrm{L}$ MUF-substrate solution and $50 \mu \mathrm{L}$ MES-buffer, which were pre-pipetted in deep-well microplates (96-well, $0.5 \mathrm{ml}$, HJ-Bioanalytik GmbH, Monchengladbach, Germany). Fluorescence was measured at an excitation wavelength of $360 \mathrm{~nm}$ and an 
emission wavelength of $460 \mathrm{~nm}$ at 0,30 and 60 min after reaction, with a Victor3 1420-050 Multilabel Counter (PerkinElmer, Waltham, MA, USA). Calibration curves were included in every series of enzyme measurements. Enzyme activities were expressed as MUF release in nanomoles per gram bulk soil dry weight per hour $\left(\mathrm{nmol} \mathrm{g} \mathrm{g}^{-1} \mathrm{~h}^{-1}\right)$.

\subsection{Statistical analysis}

Data were analyzed by ANOVA procedure using the SPSS for Windows, version 11.5 (SPSS Inc., Champaign, IL). Three-way ANOVA was used to analyze the individual and interactive effects of warming, incubation temperature and tillage systems on the $\mathrm{CO}_{2}$ effluxes, soil labile carbon and extracellular enzyme activities. Differences were considered significant at $P<0.05$. Means of main effects were compared using the least significant difference (LSD) test after a significant ANOVA test.

\section{Results}

\section{1. $\mathrm{CO}_{2}$ efflux and $\mathrm{Q}_{10}$}

$\mathrm{CO}_{2}$ efflux from soil incubated at three temperatures showed lasting effects of field warming on SOM decomposition (Fig. 1). $\mathrm{CO}_{2}$ efflux rates were significantly increased in tilled soil under warming (TW) compared to non-warmed (TN) at all three incubation temperatures by 26,13 and $12 \%$ for 15,21 and $27{ }^{\circ} \mathrm{C}$ incubation temperatures, respectively. Similar results were found between $\mathrm{NW}$ and $\mathrm{NN}$, with 26,15 and $12 \%$ higher $\mathrm{CO}_{2}$ fluxes under the warmed, no-till soil. Thus, $17 \%$ more $\mathrm{CO}_{2}$ was released on average due to exposure to warming regardless of the tillage system. Between tillage systems, $\mathrm{CO}_{2}$ effluxes tended to higher under $\mathrm{NN}$ than TN by $2.8,7.9$ and $19.2 \%$ for 15,21 and $27{ }^{\circ} \mathrm{C}$, respectively; while greater increases were found under NW than TW with 3.2, 7.9 and $18.8 \% \mathrm{CO}_{2}$ efflux was significantly affected by warming $(<0.001)$, incubation temperature $(<0.001)$ and tillage system $(<0.001)$ (Table 1 ), but the significantly effect of the interaction of three factors was only observed between incubation $\times$ tillage system $(<0.001)$.

The patterns of the ratio of the cumulative $\mathrm{CO}_{2}$ flux for warmed to non-warmed soil were similar for No-Till and Till systems (Fig. 2), indicating that the $\mathrm{CO}_{2}$ flux was not sensitive enough to

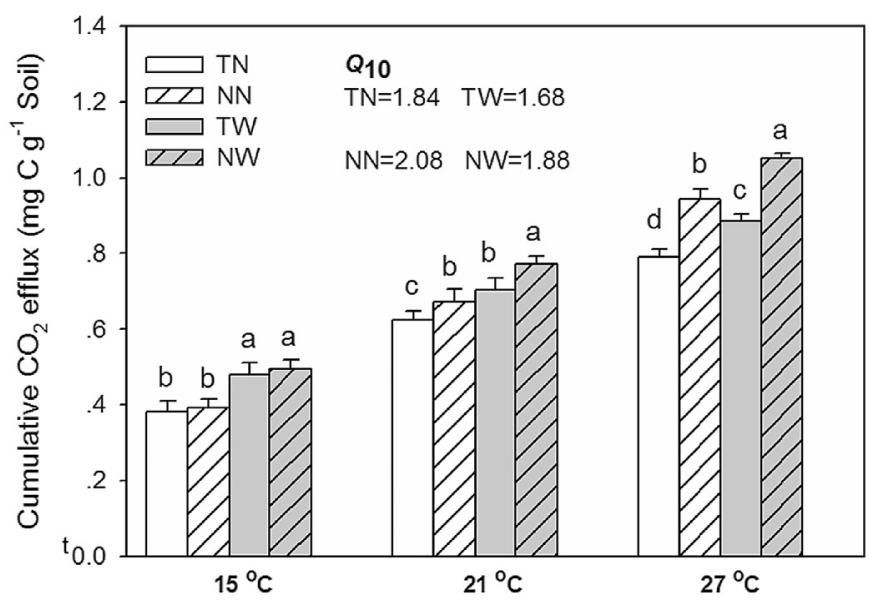

Fig. 1. Cumulative $\mathrm{CO}_{2}$ effluxes $( \pm \mathrm{SE})$ from $\mathrm{TN}, \mathrm{TW}, \mathrm{NN}$ and $\mathrm{NW}$ under three temperatures $\left(15,21\right.$ and $\left.27{ }^{\circ} \mathrm{C}\right)$. Different lowercase letters show the significant differences at same temperatures among the four treatments. TN, Till + no warming; TW, Till + warming; NN, No-Till + no warming; NW, No-Till + warming. reflect the differences between land use systems. However, considering the incubation temperatures, the greatest relative effect of warming on cumulative $\mathrm{CO}_{2}$ efflux was observed at $15^{\circ} \mathrm{C}$ for both No-Till and Till systems. For $27{ }^{\circ} \mathrm{C}$ incubation, a sharp increase was observed during the first 6 days, followed by slow deceleration back to the initial level. These changes in relative $\mathrm{CO}_{2}$ flux between warmed and non-warmed soil indicated that with increasing incubation temperature, the pool of easily available $\mathrm{C}$ for decomposition decreased much faster under warmed vs. nonwarmed treatments. Thus, the rate of SOM decomposition was not constant during incubation.

In contrast to the relative increase in $\mathrm{CO}_{2}$ flux by warming, the $Q_{10}$ parameter revealed differences between warmed and nonwarmed soils. The field warmed soils had a significantly greater $Q_{10}$ of $\mathrm{CO}_{2}$ flux during days $0-6$ of incubation than non-warmed soils, while the reverse was observed for days 35-59 (Fig. 3). The $Q_{10}$ changes implied that the temperature sensitivity of SOM decomposition was strongly affected by the 4-years of exposure to warming due to either altered structure and activity of the microbial communities or the quality of the SOM. Clearly, both features are closely connected and most likely changed together.

\subsection{Labile organic carbon}

The labile extracted organic compounds significantly declined during incubation. After 59 days, soil microbial biomass carbon (MBC) declined during incubation on average for the three temperatures by 33 and $42 \%$ for TN and TW, respectively, compared to the start of incubation. The decreases for NN and NW were smaller and amounted to 23 and 30\%, respectively (Fig. 4). In contrast, the average decline in dissolved organic carbon (DOC) between warmed and non-warmed soils was similar at $28 \%$ for Till and NoTill systems.

\subsection{Extracellular enzyme activity}

All extracellular enzyme activities (EEA) were significantly higher in warmed soils under No-Till, whereas no effect of warming was observed between TN and TW (Fig. 5). Warmed soil under NoTill demonstrated significantly higher EEA than non-warmed soils for chitinase and sulfatase at $15{ }^{\circ} \mathrm{C}$ by 35 and $182 \%$, and by 96 and $63 \%$ at $21^{\circ} \mathrm{C}$, respectively. A significant increase in $\beta$-Glucosidase (responsible for the splitting of complex organics, e.g., cellulose to glucose) indicated an increase in the organic substrates available for microorganisms. The highest activity of $\beta$-Glucosidase, occurring at $21^{\circ} \mathrm{C}$, may reflect the optimum temperature of this enzyme, whereas available $\mathrm{N}$ and $\mathrm{S}$ were not limiting for the microorganisms (the activities of chitinase and sulfatase were lower or unchanged from the initial soil, respectively) (Fig. 5). All three EEA were significantly affected by warming, incubation temperature and tillage system (all $P<0.05$ ). The interactive effects of warming with tillage, and incubation temperature with tillage also significantly affected the three enzyme activities (all $P<0.05$ ) (Table 1 ).

\section{Discussion}

\subsection{Lasting effect on soil $\mathrm{CO}_{2}$ efflux}

Higher $\mathrm{CO}_{2}$ efflux from field warmed soils relative to nonwarmed was observed under same incubation temperatures (Fig. 1). Warming accelerated SOM decomposition and strongly increased soil respiration (Lu et al., 2013; Wang et al., 2014). The lasting positive effects of warming on soil respiration has been observed, i.e. there was increased $\mathrm{CO}_{2}$ efflux from pre-warmed soil relative to a control after warming was switched off under field 
Table 1

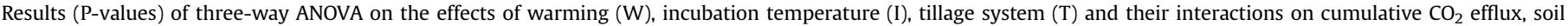
microbial biomass carbon (MBC), dissolved organic carbon (DOC), $\beta$-Glucosidase, Chitinase and Sulfatase.

\begin{tabular}{|c|c|c|c|c|c|c|}
\hline Source of variance & $\mathrm{CO}_{2}$ efflux & $\mathrm{MBC}$ & DOC & $\beta$-Glucosidase & Chitinase & Sulfatase \\
\hline W & $<0.001$ & $<0.001$ & $<0.001$ & $<0.001$ & $<0.001$ & $<0.001$ \\
\hline I & $<0.001$ & $<0.001$ & $<0.001$ & $<0.001$ & 0.004 & 0.001 \\
\hline $\mathrm{T}$ & $<0.001$ & $<0.001$ & $<0.001$ & $<0.001$ & $<0.001$ & $<0.001$ \\
\hline $\mathrm{W} \times \mathrm{I}$ & 0.703 & 0.919 & 0.789 & 0.307 & 0.002 & 0.024 \\
\hline $\mathrm{W} \times \mathrm{T}$ & 0.337 & 0.187 & 0.303 & $<0.001$ & $<0.001$ & $<0.001$ \\
\hline $\mathrm{I} \times \mathrm{T}$ & $<0.001$ & 0.128 & 0.791 & $<0.001$ & 0.031 & $<0.001$ \\
\hline $\mathrm{W} \times \mathrm{I} \times \mathrm{T}$ & 0.987 & 0.956 & 0.760 & 0.380 & 0.018 & 0.001 \\
\hline
\end{tabular}

conditions (Hartley et al., 2007). In our study, the lasting effect indirectly indicated there was in situ thermal adaptation of microbial processes (Bradford, 2013). The lower $Q_{10}$ values during the whole incubation period under warmed than non-warmed soils for both tillage practices meant that four years warming decreased temperature sensitivity (Fig. 1). Thus, thermal adaptation of soil respiration involved weaker response of mass-specific respiration to temperature change (Atkin and Tjoelker, 2003). Our results were supported by previous findings demonstrating that long-term warming can change the mechanisms of SOM turnover (Billings and Ballantyne, 2013).

\subsection{Response of labile organic carbon and $Q_{10}$}

Our results showed a rapid decline in the relative increase of soil respiration rate with time especially at 15 and $27{ }^{\circ} \mathrm{C}$ (Fig. 2) and

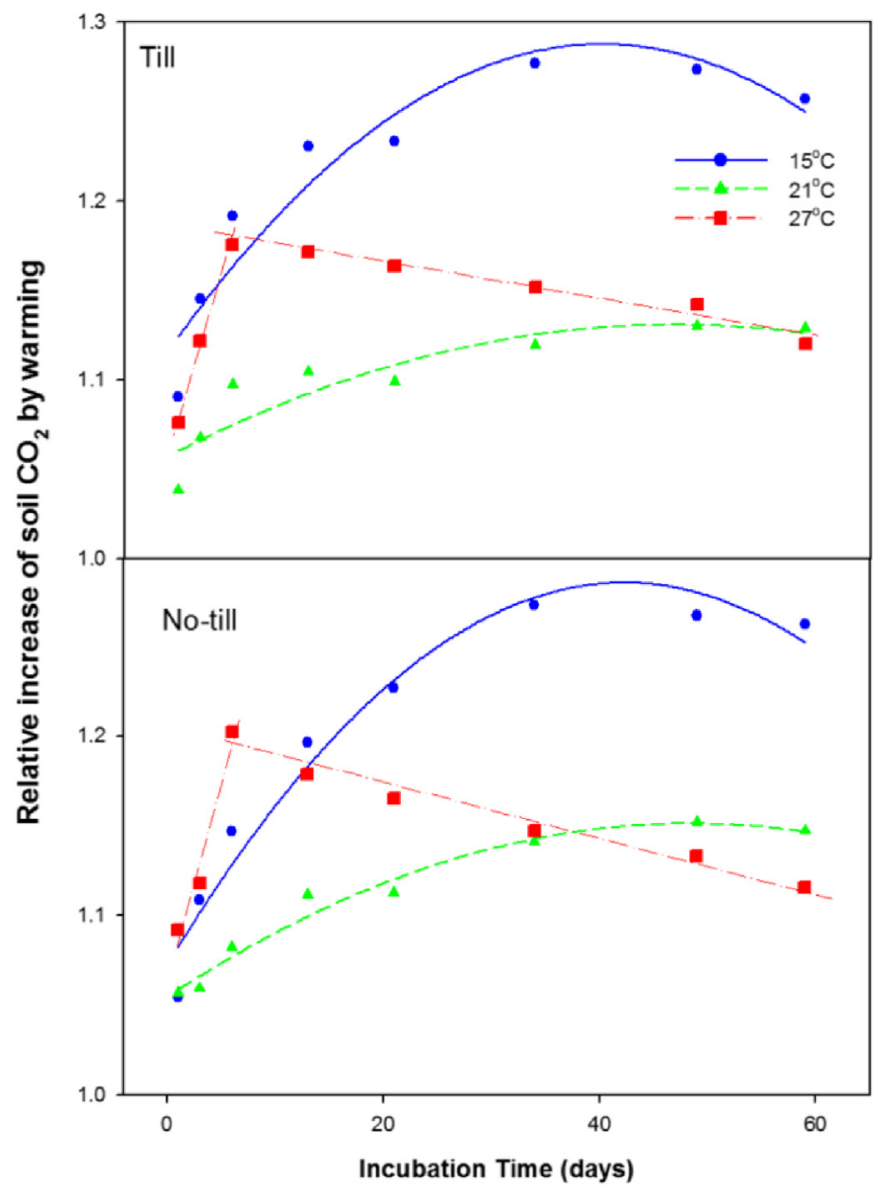

Fig. 2. Relative increase in $\mathrm{CO}_{2}$ efflux from soil by warming, i.e., ratio of Warmed/Nonwarmed for tilled soil (Top) or soil without tillage (Bottom). more intensive substrate depletion in warmed soils with higher incubation temperature (Fig. 4). The supply of available substrate could govern the sensitivity of microbial decomposition of SOM to temperature (Bell et al., 2010; Bell and Henry, 2011). Similarly, substrate depletion under sustained experimental warming was indicated by higher $\mathrm{CO}_{2}$ efflux under warmed relative to nonwarmed soils (Melillo et al., 2002; Bradford et al., 2008). The decline in MBC with increasing temperature (Fig. 4) was likely caused by higher microbial activity which resulted in rapid depletion of cell reserves and easily available substrates in soil (Knorr et al., 2005; Bradford et al., 2008).

The decrease of easily available substrate could limit the temperature sensitivity of SOM decomposition (Eliasson et al., 2005; Fissore et al., 2013). In the laboratory, ample substrate leads to higher $Q_{10}$ in warmed soil than in non-warmed soil during the first 1-2 days of incubation (Piva et al., 2012; Nie et al., 2013). This is consistent with our results (Fig. 3) in which higher microbial activity in warmed soils decomposed labile substrates faster, leading to higher $(P<0.05) Q_{10}$ values for warmed compared to non-warmed soils during the first 6 days. The substrates depleted faster during the incubation under higher temperature, which may have consequently resulted in the decreased temperature sensitivity. The depletion of labile substrates declined the initially high $\mathrm{CO}_{2}$ efflux to lower levels at the end of incubation. This decline led to lower $(P<0.05) Q_{10}$ in warmed soils than the non-warmed (Fig. 3) and decreased $Q_{10}$ in warmed vs. non-warmed treatments during the complete 59-day incubation (Fig. 1). Thus, our results indicated that the lasting effect of warming on SOM decomposition could be restricted by substrate depletion.

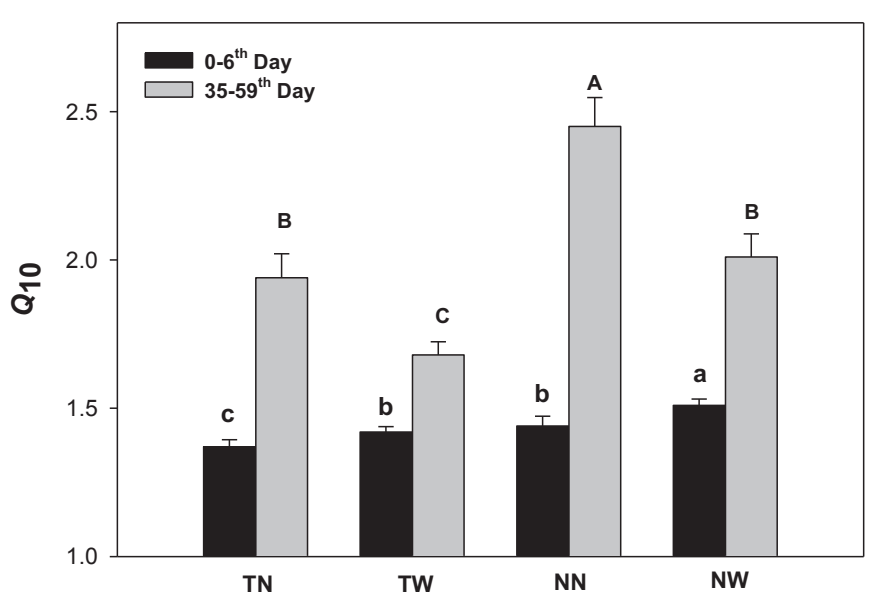

Fig. 3. $\mathrm{Q}_{10}$ values during the beginning and end periods: first 6 days and from day 35 to 59 of incubation. The lowercase/uppercase letters represent significant differences of 0-6th day/35-59th day among four treatments respectively. TN, Till + no warming; TW, Till + warming; NN, No-Till + no warming; NW, No-Till + warming. 


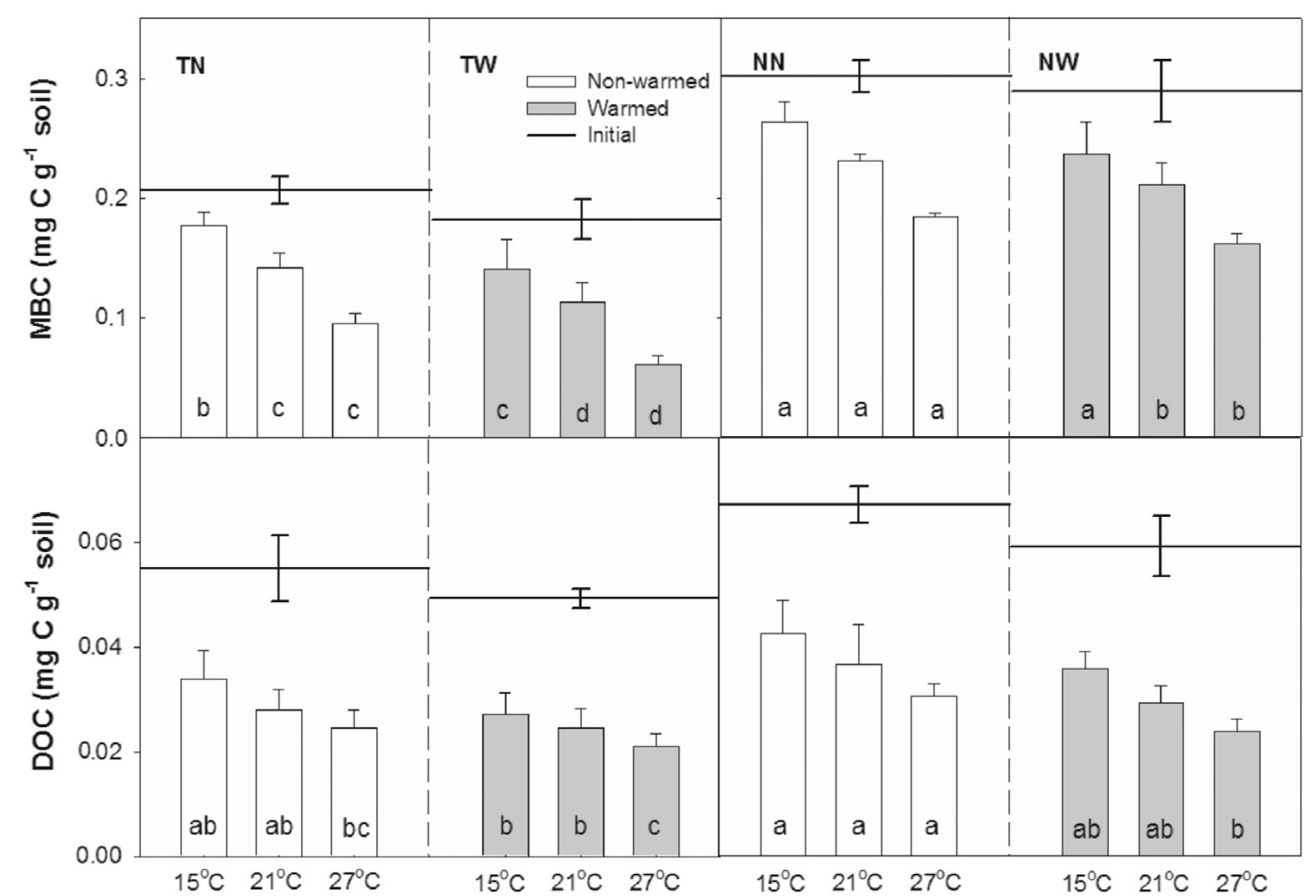

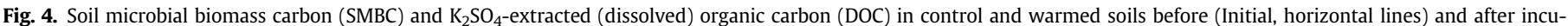

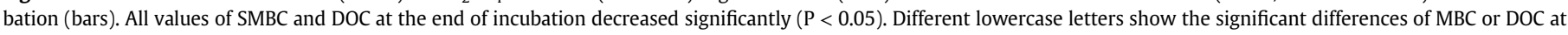
same temperatures among the four treatments. TN, Till + no warming; TW, Till + warming; NN, No-Till + no warming; NW, No-Till + warming.

\subsection{Response of extracellular enzyme activity}

In our study, warming significantly increased EEA under No-Till with small but significant effect on Till soils. This finding answered our research questions in a way that warming promoted change of EEA through a set of direct and indirect effects such as increased plant depositions, possible shifts in microbial community structure and other effects (discussed below). Our study showed that such positive effects of warming on EEA were dependent upon the tillage system and only held true for No-Till (Fig. 5). In addition to the direct temperature effects on EEA, warming indirectly controls EEA through soil moisture and plant physiology (Bell et al., 2010; Henry, 2012) which may offset the apparent warming-induced EEA increase. Excessive drying of soils under warming is expected to decrease the EEA because of desiccation and limited substrate supply of plant-derived deposits. However, no clear effects of soil moisture loss on EEA under warming have been reported (Allison and Treseder, 2008; Jing et al., 2014). Irrigation maintained the soil at a relatively high moisture level (Hou et al., 2014) thereby preventing any negative effects of warming on EEA. Plant physiology may also affect substrate availability by deposition of labile $C$ (Tilman et al., 2009; Allison et al., 2010). On the same experimental site, greater root biomass was measured under No-Till relative to Till treatment in the $0-10 \mathrm{~cm}$ soil layer (Hou et al., 2015). Direct positive relationship between root biomass and EEA increase was reported (Geisseler et al., 2011). Altogether, maintenance of soil moisture and greater root biomass near the surface both should contribute to the increased EEA with warming in our experimental site.

Between the two tillage treatments, the response of EEA to warming was much less pronounced under Till as compared to NoTill. This was explained by differences in amount and quality of SOM between the two treatments. Thus, significantly lower SOC, total N (See Supplementary Tab. S1), MBC and DOC (Fig. 4) contents were measured near the surface under Till than No-Till resulting in overall lower availability of substrate for microorganisms in the Till system.

\subsection{Effects of tillage systems}

Higher $\mathrm{CO}_{2}$ efflux was measured under No-Till relative to Till for warmed and non-warmed soils, especially at 21 and $27^{\circ} \mathrm{C}$ (Fig. 1). No-Till has been observed to strongly increase soil microbial biomass and activity, and to release more $\mathrm{CO}_{2}$ during incubation relative to tilled soil (Wagai et al., 2013). However, the findings of higher $\mathrm{CO}_{2}$ efflux due to warming under no-till compared to tillage treatment measured in the laboratory should be cautiously extended to field conditions. The natural distribution of crop residue under No-Till as compared to tilled soil provides physical protection by occlusion in aggregates which limits SOM mineralization in the field. Sampling of soil inevitably affects soil structure and decreases the physical protection of SOM. As all of the soil samples were collected and sieved in a similar manner and there was no significant difference in total soil organic carbon content between soils of each tillage treatment (See Supplementary Tab. $\mathrm{S} 1$ ), the observed differences in temperature sensitivity of $\mathrm{CO}_{2}$ flux of the two tillage systems cannot be explained solely by changes in physical protection of SOM. Furthermore, our field observations revealed a decrease in soil $\mathrm{CO}_{2}$ emissions over time under Till, while it consistently increased under No-Till treatment over the three wheat seasons and two maize seasons under warming (Hou et al., 2014), hereby supporting the observed patterns in the current study.

To the best of our knowledge, this is the first study that compared the response of SOM decomposition to warming under long-term Till and No-Till farming. The lasting positive effects of warming on the SOM decomposition and decline of $Q_{10}$ were observed for the two tillage systems indicating thermal adaptation of microbial community to higher in situ temperature. Comparing the two tillage practices, higher $Q_{10}$ under No-Till than Till (Fig. 1) 


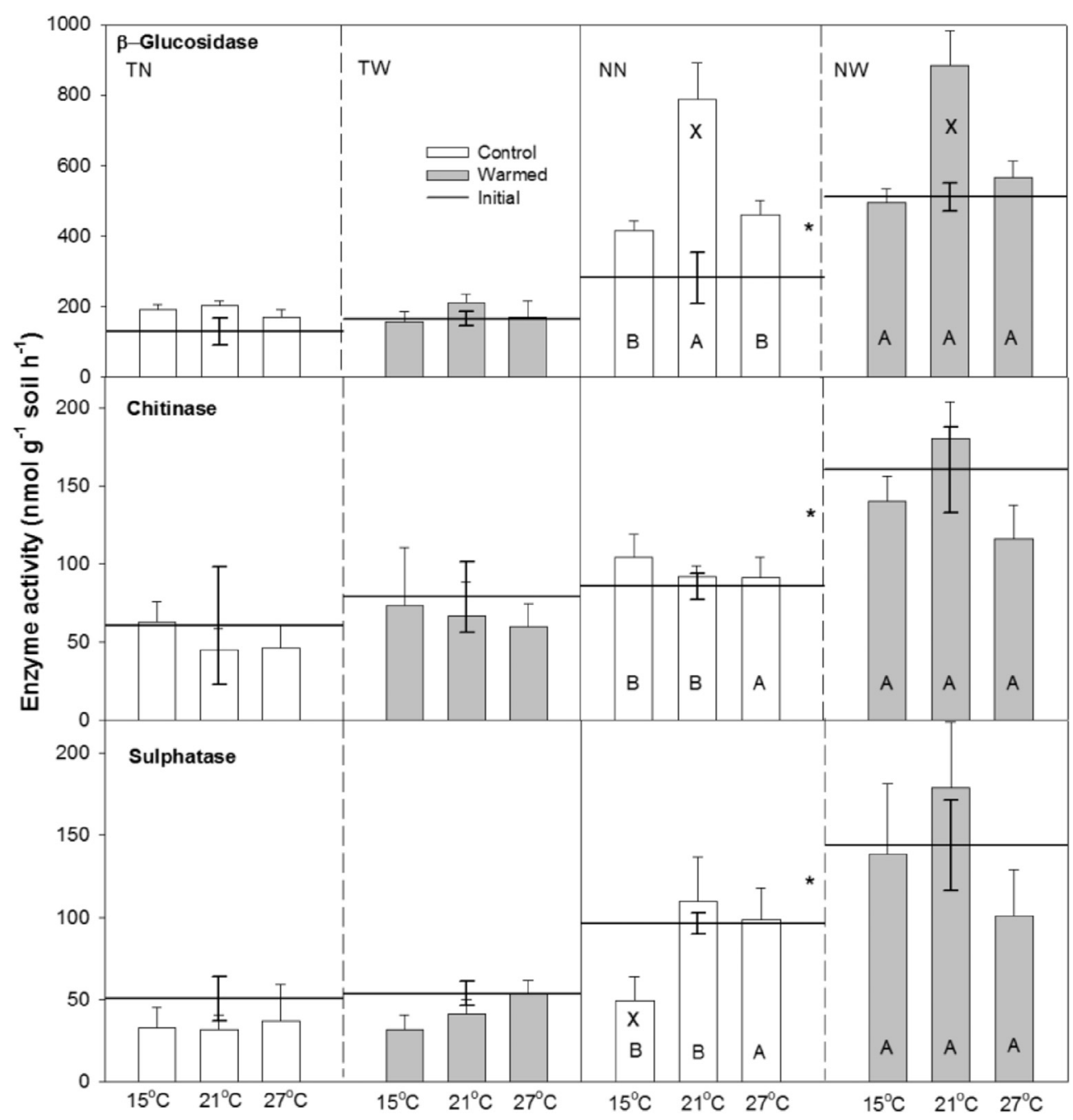

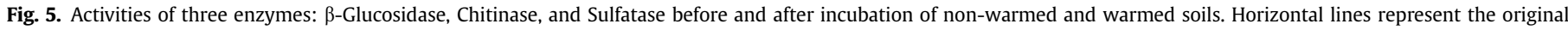

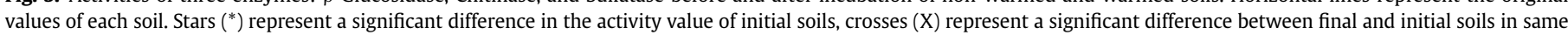

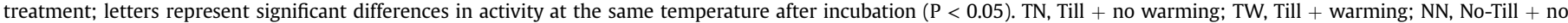
warming; NW, No-Till + warming.

meant higher temperature sensitivity of SOM decomposition thereby answering our second research question. Thus, the retention of residues on the surface by No-Till makes the easily available substrate more vulnerable to warming effects on $\mathrm{C}$ decomposition and $\mathrm{CO}_{2}$ efflux. Our results indicate that there is a need to consider contrasting responses to tillage management for global warming when predicting soil $\mathrm{C}$ pools in croplands.

\section{Conclusions}

After four years of in situ soil warming, the SOM decomposition was more intensive in warmed soil as compared with non-warmed soil. This effect of warming on soil microorganisms lasted for at least two months. Based on the increased activities of measured enzymes ( $\beta$-Glucosidase, Chitinase and Sulfatase), we conclude that the microorganisms were more active under warming, probably because of thermal adaptation of microorganisms. Such warminginduced EEA were most pronounced under No-Till system. At the same time, substrate depletion was found to limit the soil $\mathrm{CO}_{2}$ efflux and the temperature sensitivity of SOM decomposition. Thus, $C$ sequestration in the topsoil under No-Till system would be more vulnerable to environmental changes as compared with the Till system. The $\mathrm{C}$ balance in croplands should be evaluated to consider differences in SOM decomposition between Till and No-Till systems under increasing temperature.

\section{Acknowledgments}

K. Schmidt, I. Ostermeyer and S. Enzmann provided laboratory assistance with sample analysis. This work, including the maintenance of the long-term soil warming experiments, was supported by a grant from the Chinese Academy of Sciences (XDA05050502), and National Natural Science Foundation of China (31300373), and National High-tech Research and Development Program of China (2013AA102903). We express our sincere thanks to the reviewers and editors for their time and effort.

\section{Appendix A. Supplementary data}

Supplementary data related to this article can be found at http:// dx.doi.org/10.1016/j.soilbio.2015.12.008.

\section{References}

Allison, S.D., Treseder, K.K., 2008. Warming and drying suppress microbial activity and carbon cycling in boreal forest soils. Global Change Biology 14, 2898-2909. 
Allison, S.D., Wallenstein, M.D., Bradford, M.A., 2010. Soil-carbon response to warming dependent on microbial physiology. Nature Geoscience 3, 336-340.

Atkin, O.K., Tjoelker, M.G., 2003. Thermal acclimation and the dynamic response of plant respiration to temperature [Review] Trends in Plant Science 8, 343-351.

Baker, J.M., Ochsner, T.E., Venterea, R.T., Griffis, T.J., 2007. Tillage and soil carbon sequestration - what do we really know? Agriculture, Ecosystems \& Environment 118, 1-5.

Bell, T.H., Henry, H.A.L., 2011. Fine scale variability in soil extracellular enzyme activity is insensitive to rain events and temperature in a mesic system. Pedobiologia 54, 141-146.

Bell, T.H., Klironomos, J.N., Henry, H.A.L., 2010. Seasonal responses of extracellular enzyme activity and microbial biomass to warming and nitrogen addition. Soil Science Society of America Journal 74, 820-828.

Bengtson, P., Bengtsson, G., 2007. Rapid turnover of DOC in temperate forests accounts for increased $\mathrm{CO} 2$ production at elevated temperatures. Ecology Letters 10, 783-790.

Billings, S.A., Ballantyne, F., 2013. How interactions between microbial resource demands, soil organic matter stoichiometry, and substrate reactivity determine the direction and magnitude of soil respiratory responses to warming. Global Change Biology 19, 90-102.

Bradford, M.A., 2013. Thermal adaptation of decomposer communities in warming soils. Frontiers in Microbiology 4, 600-601.

Bradford, M.A., Davies, C.A., Frey, S.D., Maddox, T.R., Melillo, J.M., Mohan, J.E. Reynolds, J.F., Treseder, K.K., Wallenstein, M.D., 2008. Thermal adaptation of soil microbial respiration to elevated temperature. Ecology Letters 11, 1316-1327.

Davidson, E.A., Janssens, I.A., 2006. Temperature sensitivity of soil carbon decomposition and feedbacks to climate change. Nature 440, 165-173.

DeAngelis, K.M., Pold, G., Topcuoglu, B.D., van Diepen, L.T.A., Varney, R.M., Blanchard, J., Melillo, J., Frey, S., 2015. Long-term forest soil warming alters microbial communities in temperate forest soils. Frontiers in Microbiology 6, 104

Eliasson, P.E., McMurtrie, R.E., Pepper, D.A., Strömgren, M., Linder, S., Ågren, G.I. 2005. The response of heterotrophic $\mathrm{CO}_{2}$ flux to soil warming. Global Change Biology 11, 167-181.

Fissore, C., Giardina, C.P., Kolka, R.K., 2013. Reduced substrate supply limits the temperature response of soil organic carbon decomposition. Soil Biology \& Biochemistry 67, 306-311.

Geisseler, D., Horwath, W.R., Scow, K.M., 2011. Soil moisture and plant residue addition interact in their effect on extracellular enzyme activity. Pedobiologia $54,71-78$.

Henry, H.A., 2012. Soil extracellular enzyme dynamics in a changing climate. Soil Biology and Biochemistry 47, 53-59.

Hou, R., Ouyang, Z., Li, Y., Tyler, D.D., Li, F., Wilson, G.V., 2012. Effects of tillage and residue management on soil organic carbon and total nitrogen in the North China Plain. Soil Science Society of America Journal 76, 230-240.

Hou, R., Ouyang, Z., Wilson, G., Li, Y., Li, H., 2014. Response of carbon dioxide emissions to warming under no-till and conventional till systems. Soil Science Society of America Journal 78, 280-289.

Jing, X., Wang, Y., Chung, H., Mi, Z., Wang, S., Zeng, H., He, J.-S., 2014. No temperature acclimation of soil extracellular enzymes to experimental warming in an alpine grassland ecosystem on the Tibetan Plateau. Biogeochemistry 117, 39-54.
Knorr, W., Prentice, I., House, J., Holland, E., 2005. Long-term sensitivity of soil carbon turnover to warming. Nature 433, 298-301.

Lu, M., Xuhui, Z., Qiang, Y., Hui, L., Yiqi, L., Changming, F., Jiakuan, C., Xin, Y., Bo, L., 2013. Responses of ecosystem carbon cycle to experimental warming: a metaanalysis. Ecology 94, 726-738.

Luo, Y., Wan, S., Hui, D., Wallace, L.L., 2001. Acclimatization of soil respiration to warming in a tall grass prairie. Nature 413, 622-625.

Marx, M.-C., Wood, M., Jarvis, S., 2001. A microplate fluorimetric assay for the study of enzyme diversity in soils. Soil Biology and Biochemistry 33,1633-1640.

Melillo, J., Steudler, P., Aber, J., Newkirk, K., Lux, H., Bowles, F., Catricala, C., Magill, A., Ahrens, T., Morrisseau, S., 2002. Soil warming and carbon-cycle feedbacks to the climate system. Science 298, 2173-2176.

Melillo, J.M., Sarah, B., Jennifer, J., Jacqueline, M., Paul, S., Heidi, L., Elizabeth, B. Francis, B., Rose, S., Lindsay, S., 2011. Soil warming, carbon-nitrogen interactions, and forest carbon budgets. Proceedings of the National Academy of Sciences of the United States of America 108, 9508-9512.

Nie, M., Pendall, E., Bell, C., Gasch, C.K., Raut, S., Tamang, S., Wallenstein, M.D., 2013. Positive climate feedbacks of soil microbial communities in a semi-arid grassland. Ecology Letters 16, 234-241.

Oberbauer, S.F., Tweedie, C.E., Welker, J.M., Fahnestock, J.T. Henry, G.H., Webber, P.J. Hollister, R.D., Walker, M.D., Kuchy, A., Elmore, E., 2007. Tundra $\mathrm{CO}_{2}$ fluxes in response to experimental warming across latitudinal and moisture gradients. Ecological Monographs 77, 221-238.

Piva, J.T., Dieckow, J., Bayer, C., Zanatta, J.A., Moraes, A.D., Pauletti, V., Tomazi, M., Pergher, M., 2012. No-till reduces global warming potential in a subtropical Ferralsol. Plant \& Soil 361, 359-373.

Steinweg, J.M., Dukes, J.S., Paul, E.A., Wallenstein, M.D., 2013. Microbial responses to multi-factor climate change: effects on soil enzymes. Frontiers in Microbiology 4,146 .

Stemmer, M., 2004. Multiple-substrate enzyme assays: a useful approach for profiling enzyme activity in soils? Soil Biology and Biochemistry 36, 519-527.

Tilman, D., Socolow, R., Foley, J.A., Hill, J., Larson, E., Lynd, L., Pacala, S., Reilly, J., Searchinger, T., Somerville, C., 2009. Beneficial biofuels-the food, energy, and environment trilemma. Science 325, 270-271.

Vance, E., Brookes, P., Jenkinson, D., 1987. An extraction method for measuring soil microbial biomass C. Soil Biology and Biochemistry 19, 703-707.

Wagai, R., Kishimoto-Mo, A.W., Yonemura, S., Shirato, Y., Hiradate, S., Yagasaki, Y., 2013. Linking temperature sensitivity of soil organic matter decomposition to its molecular structure, accessibility, and microbial physiology. Global Change Biology 19, 1114-1125 (1112).

Wallenstein, M.D., McMahon, S.K., Schimel, J.P., 2009. Seasonal variation in enzyme activities and temperature sensitivities in Arctic tundra soils. Global Change Biology 15, 1631-1639.

Wang, X., Lingli, L., Shilong, P., Janssens, I.A., Jianwu, T., Weixing, L., Yonggang, C., Jing, W., Shan, X., 2014. Soil respiration under climate warming: differential response of heterotrophic and autotrophic respiration. Global Change Biology 20, 3229-3237. 